\title{
Attributes of Sustainable Event
}

\author{
S'harin Binti Mokhtar and Yi-Shin Deng
}

\begin{abstract}
The concept of sustainability in event has infiltrate lately since society gain greater understanding towards impacts that caused by event. In order to gain understanding on how an event embedding sustainable development to reduce the event impacts, Olympic Games had chosen as case study in this study because this mega-event had been successfully embedded sustainability principles and objectives in all areas of Games planning. Content analysis was carried out in eight official reports published by the organizers of Olympic Games from the year of 1994 to 2012 to identify the sustainable practices in Olympic Games. Based on the data from content analysis, six attributes of sustainable event were provided as a preference for other event organizers in organizing a sustainable event in the future.
\end{abstract}

Index Terms - Olympic games, sustainable event, sustainable development, attributes.

\section{INTRODUCTION}

Globally, many countries are increasingly utilizing events as vehicles for regional development as they continue to demonstrate a capacity to generate positive outcomes for host regions. For example, Olympic Games as major international mega-events represent a significant economic, political and social opportunity for the host country. The Games can provide an excellent opportunity for local businesses and enhance the economic benefits for host countries by upgrading and introducing them internationally. Hosting mega-events increases the attention to provide appropriate places and infrastructure to host those events which is able to enhance a better quality of life for local communities, giving a positive impact on citizens as a result of close contact with other communities by gaining social and cultural experiences.

However, at the same time, staging an event as complex as the Olympic Games has a significant negative impact on the host city. Although the staging of a mega-sporting event generated new jobs, there are only a limited of new permanent jobs and majority of the anticipated jobs are low-pay and short-lived [1]-[3]. Hall and Hodges [4] claimed that the building of event-related infrastructure can involve housing relocation which can lead to a rise in rents and house prices. Consequently, this can cause problems for people living on low incomes in these areas.

Mega-event may also pose additional environmental problems especially when temporary structures are built for

Manuscript received October 21, 2014; revised January 4, 2015.

S'harin Binti Mokhtar is with the National Cheng Kung University, Tainan City, 701 Taiwan R.O.C. (e-mail: sharin2901@ gmail.com).

Yi-Shin, Deng is with the National Taiwan University, Taipei City, 10617 Taiwan R.O.C. (e-mail: yishin.deng@gmail.com). the needs of the event. In this case, the practices of disposing of such material, which cannot be recycled, fail to quality as ecologically sustainable development. For example, at the Atlanta Games, four sports were hosted in temporary facilities which had to be demolished after the Games because of their limited usefulness to the local community [5].

Given the increasing attention and importance of sustainability related research, this study believe it is useful to provide a comprehensive review of sustainable practices related research in Olympic Games. The purpose of this study is to review and analyze official report of Olympic Games related to sustainable practices. The details of review are as follows.

1) Publication year of official report related to sustainable practices in Olympic Games;

2) Geographical locations of the Olympic Games;

3) The Organizers of the Olympic Games

Second, research focus in Olympic Games related to sustainable practices in the aspects of environmental, social and economy. Third, a set of sustainable event attributes will be provided and end with conclusion.

\section{LITERATURE REVIEW}

\section{A. Sustainable Event}

World Commission on Environment and Development defines sustainable as "meeting the needs of the present without compromising the ability of future generations to meet their needs" [6]. A sustainable event is one designed, organized and implemented in a way that minimizes potential negative impacts and leaves a beneficial legacy for the host community and all involved. Sustainable event should develop from the requirements of the organization to consider economic, social and environmental impact [7] from the production process until the products or services has delivers to customer by applying sustainable development in the process. It posits a desirable future state for human societies in which living conditions and resource-use meet human needs without undermining the sustainability of natural systems and the environment, so that future generations may also have their needs met. Most definitions of sustainable development encompass the idea that there are three interdependent pillars of sustainable development: environmental, economic and social. The objective of sustainable development is to maximize the goals across all three systems. Critically, the understanding that each of the system goals is socially constructed and that achieving sustainable development requires trade-offs; choices have to be made at particular points in time and at particular scales as to what is being pursued and how, and sustainable development requires recognition of the costs involved for particular interests and for groups of people. 


\section{B. Sustainable Development}

To achieve sustainability in organizing an event, integration of sustainable development able to reduce the negative impact that cause by event. Sustainable development is not a new concept in achieving sustainability. This is because the chief focus of sustainable development is on society, and its aim is to include environmental considerations in the steering of societal change, especially through changes to the way in which the economy functions. Promoting sustainable development is about steering societal change at the interface between:

1) Environmental: Involves the contribution of both the economic and the social and their effect on the environment and its resources.

2) Social: Relates to human rights and values, relationships and institutions.

3) Economic: this concerns the allocation and distribution of scarce resources.

These are known as the three dimensions or pillars of sustainable development [8].

As shows in Fig. 1, these three pillars of sustainable development emphasize the links among these three dimensions, their long-term complementarities, and the need for balancing them when conflicts arise in the short-term.
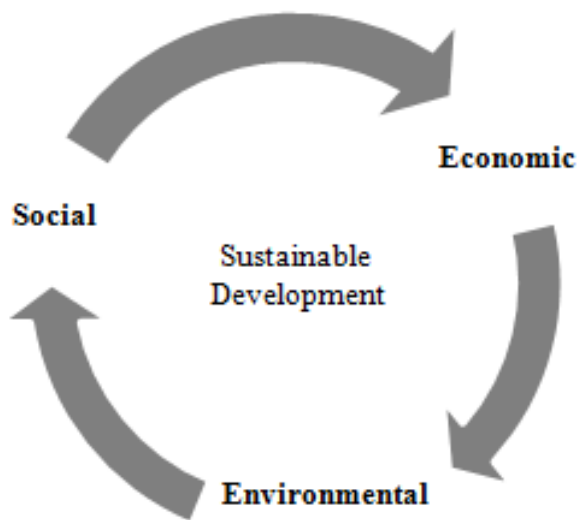

Fig. 1. Sustainable development: Linking economic, environmental and social [9].

By promoting concept of sustainable development in event, it able to covers the requirements for strong and durable economic growth, such as preserving financial stability, a low and stable inflationary environmental, and capacities to invest and innovate in the aspect of economic sustainability; focuses on maintaining the integrity, productivity and resilience of biological and physical systems, and on preserving access to a healthy environment in the aspect of environmental sustainability; it also emphasizes the importance of high employment, of safety nets capable to adapt to major demographic and structural changes, of equity and of democratic participation in decision making in the aspect of social sustainability. Enshrined in the concept of sustainable development is a concern with the quality of economic growth as well as its quantity, and with human well being alongside economic growth.

\section{Overview of Olympic Movement's Effort towards Sustainability}

Due to overconsumption of natural resources driven by unprecedented economic growth, globalization and the unavoidable rise in world population is clearly not sustainable in the long term. Notice that, Olympic Movement (composed of the three main constituents: International Olympic Committee, International Sport Federations and National Olympic Committees) had putting effort to promote sustainable development in sporting world. Thus, in June 1992, world leaders were met in Rio de Janeiro for the United Nations Conference on Environment and Development (UNCED), also known as The Earth Summit to brought environmental and sustainable development issues into the global political arena. A plan of action for the introduction of sustainable development in the 21 st century had been proposed in the meeting which known as Agenda 21 to encourages national and local political bodies, non-governmental organizations (NGOs) and citizen groups to recognize that environmental and development concerns are linked, and a global partnership for sustainable development would improve the living standards for all, better protected and managed ecosystems and a safer and more prosperous future [10].

The organizer of Olympic Games, National Olympic Committees (NOCs) had signed the Earth Pledge at the Games of the XXV Olympiad, committing to making the Earth a safe place and become one of the first organizations to pick up the UNCED baton [11]. In 1994, International Olympic Committee's partnership forged with the UN Environment Program (UNEP). This cooperative agreement is to cooperate and contribute to the education of the sporting world and young people in ecological sustainability. Then, the Olympic Movement articulated its determination to incorporate sustainability principles at the 100th Olympic Congress in the same year and in the Olympic Charter in 1996 [12].

In the year of 1996, International Olympic Committee established the environments as the third pillar of Olympism alongside sport and culture. In the following year, the International Olympic Committee publishes the Manual on Sport and the Environment to raise awareness and educational campaigns for all the members of the Olympic [13]. The aim of the manual is to underline the importance of a clean environment and sustainable development, enable constituents to improve their quality of life without compromising that of future generations.

In 1999, Olympic Movement adopted Agenda 21: Sport for Sustainable Development [14]. Based on the UNCED model, it lays down a clear pathway for sustainable development throughout the sporting world to reflect on what progress has been made and what still needs to be done to achieve sustainable development. International Olympic Committee had taken advantage of this global reflection to review how the sporting world has embraced the challenges set out in the Agenda 21, and to reaffirm its commitment to implementing measures that had brought sustainability to the forefront.

In the year of 2000, International Olympic Committee had published the Be a Champion for the Environment booklet for Summer Olympic Games focusing on educational campaigns for the member of Olympic and athletes on the importance of green environment. The following year, the same booklet had been published for the Winter Olympic Games. 
Then, in 2002, International Olympic Committee forms a partnership with the United Union (UN) Interagency Task Force Sport for Development and Peace that bring together UN funding, applied programs and specialized agencies that use sport in their activities. Besides that, the International Olympic Committee launches the Olympic Games Knowledge Services (OGKS) to ensure effective sharing of acquired knowledge [15].

The International Olympic Committee with 35 Olympic International Federation (IFs) had published the Sport, Environment and Sustainable Development guide in 2005 to help the members of Olympic to implement Agenda 21 recommendations. As what the International Olympic Committee did to promote sustainable development and environmental policies in Olympic Games, the organization received the UNEP Champion of the Earth Award in 2007 [16] and granted as official observer status by UN General Assembly (UNGA) in 2009 [17].

Since then, an independent Environmental Assessment of Beijing 2008 Olympic Games [18] and Global Reporting Initiative (GRI) event organizers' sector supplement [19] are published benefited from the expertise from previous Olympic Games to share the knowledge of sustainable development from their experience. The Olympic Movement is also the key player of the development of the ISO 20121 international standard to help event organizers to map the economic, environmental and social impacts of event organizations [20].

\section{Overview of Olympic Games Sustainability Initiatives}

In order to encourage the implementation of modest green actions, Olympic Movement had developed performance in the context of staging Olympic Games. In 1994, Lillehammer Winter Olympic Games becomes the first Games to explicitly include environmental consideration [21]. Together with Olympic sponsors, Norway has developed a collaborative action plan that transform the Games into an environmental showcase to handle the environmental issues such as the integrity of a bird sanctuary, deforestation and air pollution. As the result, venues of the Games were built where possible with local materials and located at location that avoid an impact on virgin forest and spectators used recyclable cutleries and utensils.

Since sustainability is a continuous project, Nagano Winter Olympic Games in 1998 had employed a number of green activities and strategies by organizers and sponsors, including use of low-emission vehicles, natural gas vehicles, electric car and hybrid buses; recyclable printer cartridges and wrapping materials and the introduction of recycling boxes at venues and throughout the host city [22].

With clear environmental guidelines and planning, Sydney Summer Olympic Games in 2000 went further when they set a green theme in its application for the Games [23]. Sydney Organizing Committee (SOCOG) not only minimizing environmental losses, they had set how to see how they could benefit the environment into the future. The core of the environment program was the green regeneration of the major site at host city. The organizers had developed parks including aboriginal forest, pedestrian, cycle trails and trees were planted surrounding the Olympic venues. After the Games, the Olympic Village which is the world's largest solar-powered suburb became a suburb complete with a retail center and a range of specialty shop which during the Games had been used for retail, administration, entertainment and athletes services. The primary school, childcare and community center built for future residents were used as the polyclinic for the Games. Furthermore, recycled building materials were used, water was purified and recycled for use in lavatories and landscape watering; natural light and ventilation were optimized in the building to reduce energy consumption and care taken to protect native flora and fauna.

In Athens Summer Olympic 2004, Athens Organizing Committee (ATHOC) had utilized innovative technology and environmental planning to minimize the Games' environmental impact [24]. The organizers had worked with sponsors to promote green technologies including hybrid car and wind and solar-powered lighting units and recycling activities which carries messages waste separation and recycling. In order to transform the local environment by improving infrastructure, a new international airport and tramway was built, the metro system was expanded, a city ring road was constructed and a computerized road-traffic management system was introduced in order to reduce the city's extremely heavy traffic and improved its air quality. Nevertheless, by realizing that the Games could provide the opportunity to spread environmental awareness and values to a large audience-in particular young people, the organizer had developed an environmental mark symbolizing the unity of humanity and nature and educational leaflets with the description of how spectators and staff could reduce their environmental impact by using public transport, not dropping litter, cutting down on waste and recycling plastic bottles in bins has been distributed during the Games.

Building on the steps taken by the previous Games, Turin's Organizing Committee (TOROC) had delivered a Winter Games that applying the principles of sustainable development [25]. The Torino Winter Games in 2006 had developed an environmental management system that for the first time in Olympic development gained ISO 14001 environmental management certificate and European Union Eco-Management and Audit Scheme (EMAS) registration that improves environmental performance, increases credibility and facilities transparency. The organizers had created a project to increase understanding of climate change issues and enable the offsetting of greenhouse-gas emissions during the games by investing in reforestation, energy efficiency and renewable energy projects. In terms of greening the event, the organizer also developed environmental criteria for all the key categories of the supply chain; and optimized the Olympic facilities. The effort of organizers had reflected their concern to deliver improvement to the area's environment as part of its legacy which all contributed to local sustainable development.

Beijing Summer Olympic Games in 2008 was a catalyst in bringing the concept of environmental sustainability into a comprehensive city development plan which is an early example of the development of the green economy [26]. The action plan of the host city was focused on making environmental protection a prerequisite in Games construction, formulating strict ecological standards to guarantee enforcement, adopting eco-friendly and energy-saving technologies and materials, and promoting the development of environment-related industries. Priority was 
given to water, air pollution and waste handling which involved environmental audit of all the organizing activities. In order to protect drinking water, clean river and lakes, enhancement of wastewater treatment to improve water quality, and improvement of sewage treatment and new treatment plants were built to handle the majority of the host city's waste water. Public transports were replaced, polluting factories were relocated and heating systems were converted since air quality was a major issue in the host city. The authorities also began promoting the sorting and recycling materials to reduce solid waste. Besides that, the Games able to organize a public-participation activity that involved local residents in planting shelter belts and grassland repair project to reduce the effects of sandstorms. The games also had a remarkable effect on people's attitudes and ways of life because there was more people to continually conscious about the practice of green consumption and participate in environmental initiative during and even after the Games.

Vancouver Winter Olympic Games in 2010 became the first Games which ensure that all building for the Games at least Leadership in Energy and Environmental Design (LEED) Silver standards, an internationally recognized green building certification system [27], [28]. This Games focused on building "increased awareness about sustainable solutions for business, communities and individuals and encourages action on local and global sustainability challenges" which taking the view that sustainable solutions that related to ecological, social and economic benefits. The organizers implement zero-solid waste management strategy that involved the stakeholders to optimize all the recycling options. In order to making the Games climate-neutral, venues were clustered to minimize energy by adopting innovative energy management and emphasis were put on smart travel with expanded public transport, smart driver training and careful planning on the road. This game also the first time in Olympic history that worked out on the indirect emissions of competitors where then developed a portfolio that promoted best practices in carbon management. Considerable care was also taken with biological diversity. The organizers also ran sustainability awareness and training programs for the Games workforce and advanced sustainability engagement using digital technology in overlooked community spaces to act as a community resource to capture and transfer knowledge on how sport can create sustainable benefits locally, regionally and internationally.

London Summer Olympic Games in 2012 was the world's first sustainable Olympic Games with the concept of "One Planet Living" [29]. The organizers embedded such concept from tendering down to the selection of sponsors. Their commitment goes beyond the concrete and mortar buildings and infrastructure, and also to raise sustainable awareness and promote new thinking and behavior in five key areas: 1) incorporate climate change awareness into its planning; 2) deliver zero-waste Games; 3) conserve diverse ecosystem and create green urban spaces; 4) host the most inclusive Games; 5) inspire people to develop sustainable lifestyle.

As conclusion, it shown that environmental understanding has come a long way in the past 20 years for Olympic Games. The concerns of London Summer Olympic Games are far more complex than the issues first brought by Lillehammer organizers in 1994. However, the aim remains the same which is for the Olympic Games to have as minimal impact as possible.

\section{RESEARCH METHODOLOGY}

This study had narrowed the scope of the review process in two ways:

1) The review was focused on "sustainability related" official reports by Olympic Games.

2) The review included relatively official reports published from 1994 to 2012 by the Games' organizers.

The specific literature search and analysis are as follows. As the first step, the literature search was based on keyword descriptors such as Olympic Games, official report, sustainability, sustainable practices, sustainable development and environmental, social and economical sustainable from electronic databases; including International Olympic Committee's official website, Emerald, Google Scholar, etc. The reference sections of reports were scanned for additional citations. As a result, the review yielded eight sustainability related reports published by the organizers of Olympic Games.

Second, content analysis was carried out in this study to analyze the full text of each report to identify the sustainable practices in Olympic Games. This process was guided by research question: What are the sustainable practices had been practice in Olympic Games? Fig. 2 represents the process of content analysis.

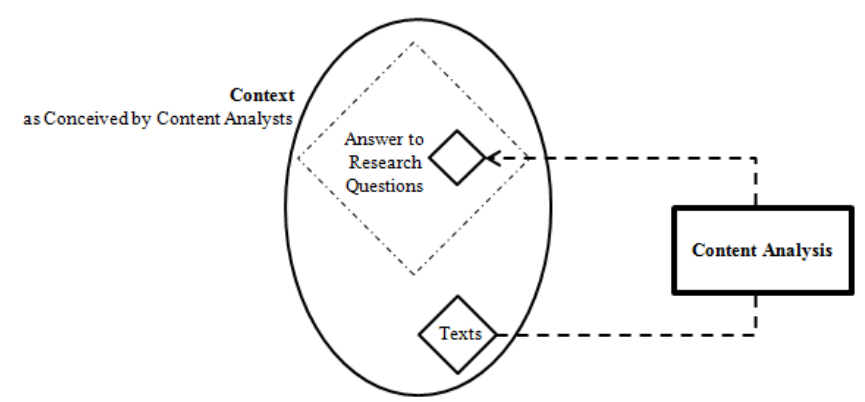

Fig. 2. Content analysis: Answering questions concerning a context of texts [30].

Next, the various reports were analyzed to find homogeneity in term of sustainability practices from each official report of Olympic Games. Sustainable practices that been identified will be organized in a data collection sheet to classify by Olympic Games that been organized. However, when data of possible co-occurrences become very large, words or sentences that are connected, belong together, or have common meanings were grouped together or merged while things whose relationships seem accidental or meaningless were separated. These steps will be repeated until there is nothing left to merge. Findings that gathered from the content analysis will help this study to provide a set of attribute for sustainable event.

\section{RESUlTS}

In this section, reports were analyzed to identify sustainable practices in Olympic Games. Selected official reports that published by the organizers of Olympic Games 
are as presented in Table I.

TABLE I: OFFICIAL REPORT OF OLYMPIC GAMES FROM THE YEAR OF 1994 TO 2012

\begin{tabular}{|c|c|c|c|}
\hline Year & Location & Olympic Games & Organizer \\
\hline 1994 & $\begin{array}{l}\text { Lillehammer, } \\
\text { Norway }\end{array}$ & $\begin{array}{l}\text { Lillehammer Winter } \\
\text { Olympic Games } \\
\text { (XVII Olympic Winter } \\
\text { Games) }\end{array}$ & $\begin{array}{l}\text { Lillehammer } \\
\text { Olympic } \\
\text { Organizing } \\
\text { Committee } \\
\text { (LOOC) }\end{array}$ \\
\hline 1998 & $\begin{array}{l}\text { Nagano, } \\
\text { Japan }\end{array}$ & $\begin{array}{l}\text { Nagano Summer } \\
\text { Olympic Games } \\
\text { (XVIII Olympic } \\
\text { Winter Games) }\end{array}$ & $\begin{array}{l}\text { Nagano } \\
\text { Organizing } \\
\text { Committee } \\
\text { (NAOC) }\end{array}$ \\
\hline 2000 & $\begin{array}{l}\text { Sydney, } \\
\text { Australia }\end{array}$ & $\begin{array}{l}\text { Sydney Summer } \\
\text { Olympic Games } \\
\text { (Games of the XXVII } \\
\text { Olympiad) }\end{array}$ & $\begin{array}{l}\text { Sydney } \\
\text { Organizing } \\
\text { Committee } \\
\text { (SOCOG) }\end{array}$ \\
\hline 2004 & $\begin{array}{l}\text { Athens, } \\
\text { Greece }\end{array}$ & $\begin{array}{l}\text { Athens Summer } \\
\text { Olympic Games } \\
\text { (Games of the XXVIII } \\
\text { Olympiad) }\end{array}$ & $\begin{array}{l}\text { Athens } \\
\text { Organizing } \\
\text { Committee } \\
\text { (ATHOC) }\end{array}$ \\
\hline 2006 & Turin, Italy & $\begin{array}{l}\text { Torino Winter } \\
\text { Olympic Games } \\
\text { (XX Olympic Winter } \\
\text { Games) }\end{array}$ & $\begin{array}{l}\text { Turin's } \\
\text { Organizing } \\
\text { Committee } \\
\text { (TOROC) }\end{array}$ \\
\hline 2008 & $\begin{array}{l}\text { Beijing, } \\
\text { China }\end{array}$ & $\begin{array}{l}\text { Beijing Summer } \\
\text { Olympic Games } \\
\text { (Games of the XXIX } \\
\text { Olympiad) }\end{array}$ & $\begin{array}{l}\text { Beijing } \\
\text { Organizing } \\
\text { Committee } \\
\text { (BOCOG) }\end{array}$ \\
\hline 2010 & $\begin{array}{l}\text { Vancouver, } \\
\text { Canada }\end{array}$ & $\begin{array}{l}\text { Vancouver Winter } \\
\text { Olympic Games } \\
\text { (XXI Olympic Winter } \\
\text { Games) }\end{array}$ & $\begin{array}{l}\text { Vancouver } \\
\text { Organizing } \\
\text { Committee } \\
\text { (VANOC) }\end{array}$ \\
\hline 2012 & $\begin{array}{l}\text { London, } \\
\text { United } \\
\text { Kingdom }\end{array}$ & $\begin{array}{l}\text { London Summer } \\
\text { Olympic Games } \\
\text { (Games of the XXX } \\
\text { Olympiad) }\end{array}$ & $\begin{array}{l}\text { London } \\
\text { Organizing } \\
\text { Committee } \\
\text { (LOCOG) }\end{array}$ \\
\hline
\end{tabular}

\section{A. Themes of Sustainable Practices}

Based on the sustainable practices that been identified in official reports of Olympic Games, a significant number of sustainable practices were identified (total of 59 sustainable practices). These sustainable practices had been grouped and merge according to the similarity of meanings to create themes. For example, Fig. 3 presents three sustainable practices that related to sustainability in event planning had been merged into one cluster and show that sustainability should embedded in an event as early as possible and even as prerequisite in event planning.

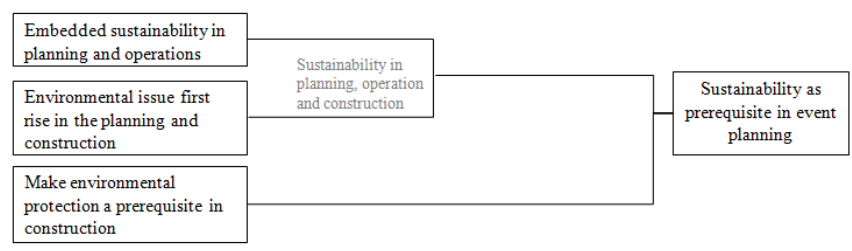

Fig. 3. Sustainability as prerequisite in event planning.

Fig. 4 shows that "local materials" had been appear twice. This has lead to the formulation of theme - local resources as first consideration.

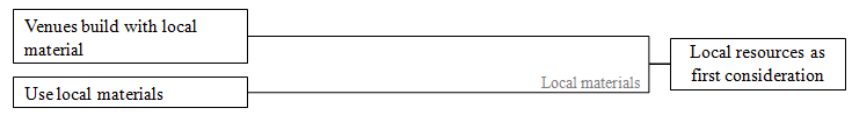

Fig. 4. Local resources as first consideration.

Fig. 5 presents five sustainable practices such as use recycle building materials when building event's venues and infrastructures, encourages event's staffs to use recyclable printing cartridge and wrapping materials, promote sorting and recycling of solid waste by introducing recycling boxes around the event's venues and encourage spectators use recycled plates and utensils. This has create the theme of adopt concept of zero-waste management practices.

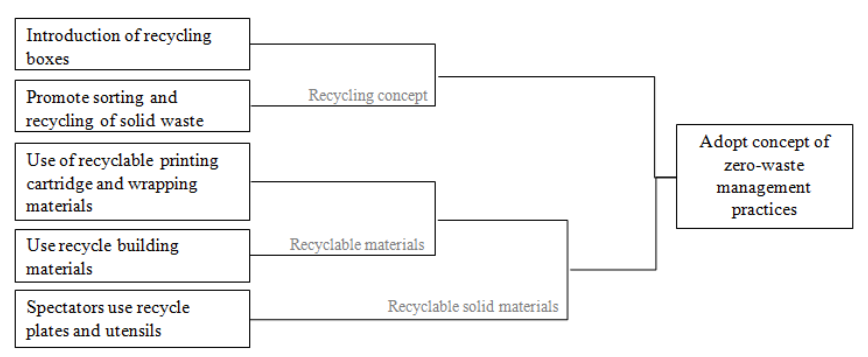

Fig. 5. Adopt concept of zero-waste management practices.

Fig. 6 presents the theme of apply sustainable approach in energy management. The theme was created by the combination of sustainable practices such as adopt eco-friendly and energy-saving technologies and materials, optimize natural light and ventilation in building and promote hybrid car and wind and solar-powered lighting units.

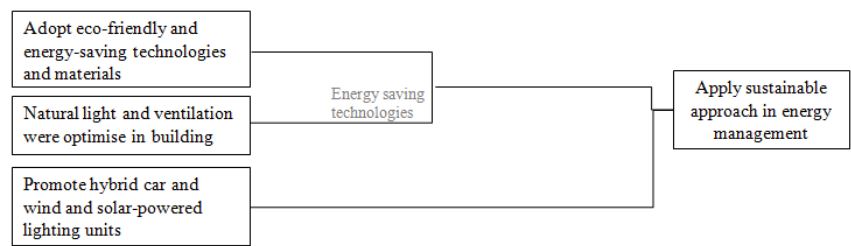

Fig. 6. Apply sustainable approach in energy management.

Fig. 7 shows the theme of adopting concept of zero-emission merged from three sustainable practices which are use of zero emission and natural gas vehicles, electric cars and hybrid buses and educe usage of persistent organic pollutant and polyvinyl chloride.

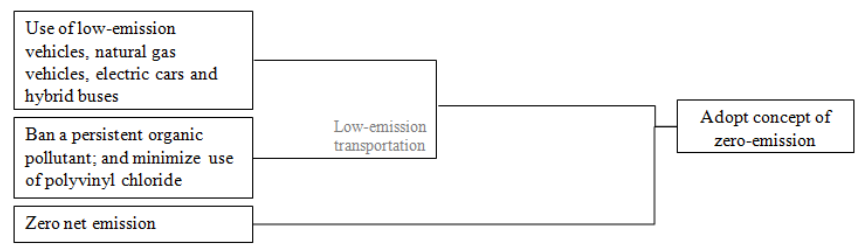

Fig. 7. Apply concept of zero-emission.

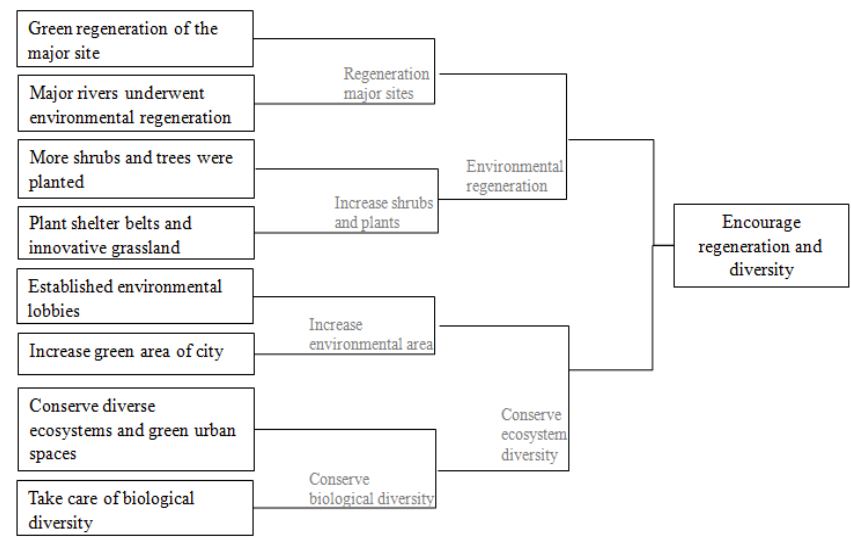

Fig. 8. Encourage environmental regeneration and diversity.

Fig. 8 presents merging of eight sustainable practices the theme of encourage environmental regeneration and diversity. The theme was created from environmental regeneration by planting more shrubs, shelter belts and 
plants; establish environmental lobbies; increase green area; and take care of biological diversity by conserve ecosystem and green urban spaces.

Fig. 9 shows environmental friendly water system as the following theme. This is merged from four sustainable practices: to improve the water systems and sewage system, purify and recycle water for use in lavatories and landscape watering; and optimize the use of water.

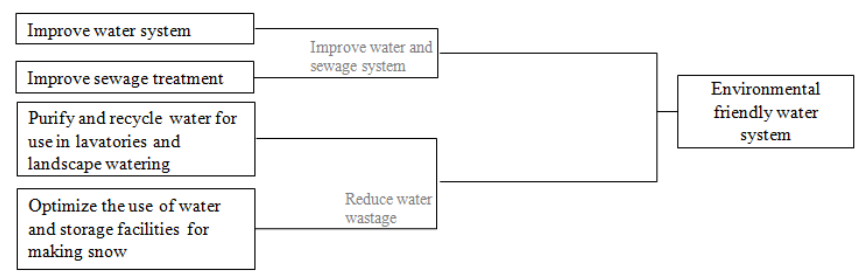

Fig. 9. Adopt environmental-friendly water system.

Fig. 10 presents merging of six sustainable practices to form the theme - improve transportation system. Sustainable practices that related to this theme are: build new international airport with fast links, replace used public transport, expand metro system, build tramway, construct a city ring road and introduce computerized road-traffic management system.

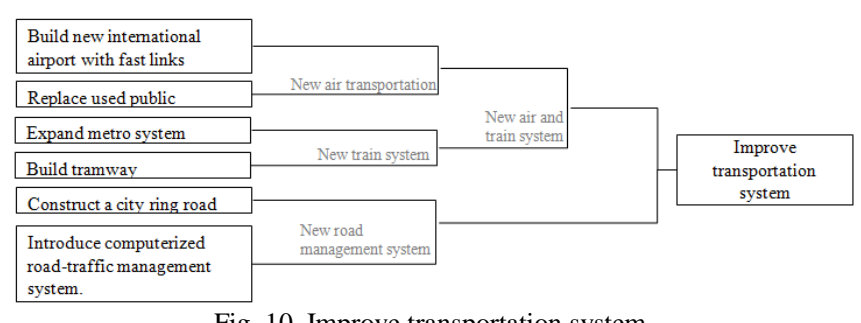

Fig. 10. Improve transportation system.

Fig. 11 presents merging of five sustainable practices to form the theme - share knowledge of sustainable practices with stakeholders. The five sustainable practices include distribution of educational leaflets with description of how to reduce environmental impact to spectators and staff; provide training of sustainable awareness to volunteers; spread message of sustainable practices to other authorities; having talk with contractors and suppliers about environmental protection; and promote recycling activities with sponsors.

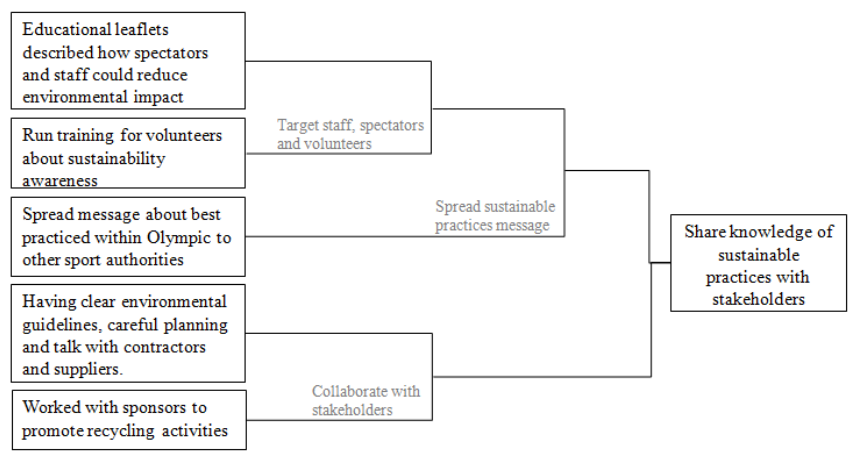

Fig. 11. Share Knowledge of sustainable practices with stakeholders.

Fig. 12 presents theme - raise public awareness at all level. This theme has been formulated from eight sustainable practices such as cleaning activities and collect waste involved local residents, green activities involved local residents, develop collaboration action plan with local residents, raise public awareness of environmental stewardship and eco-friendly consumption, a range of merchandizing with environmental mark symbolizing the unity of humanity and nature, demonstrate what sustainability involves and built awareness about solutions for communities and individuals, encourage spectators to join voluntary scheme emission and inspire people to develop more active, healthy and sustainable lifestyles.

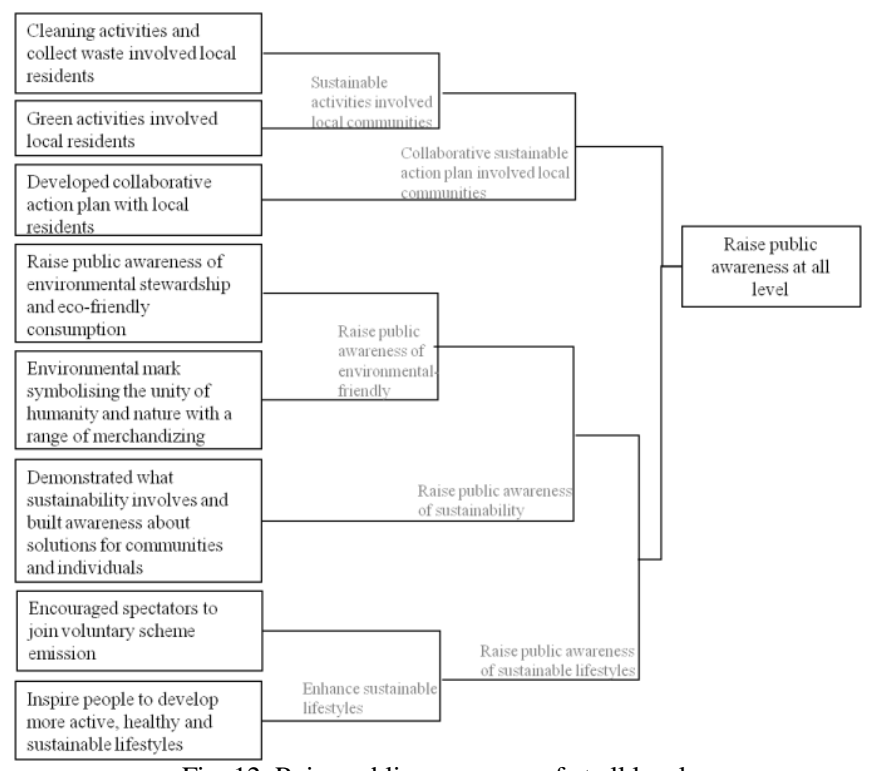

Fig. 12. Raise public awareness of at all level.
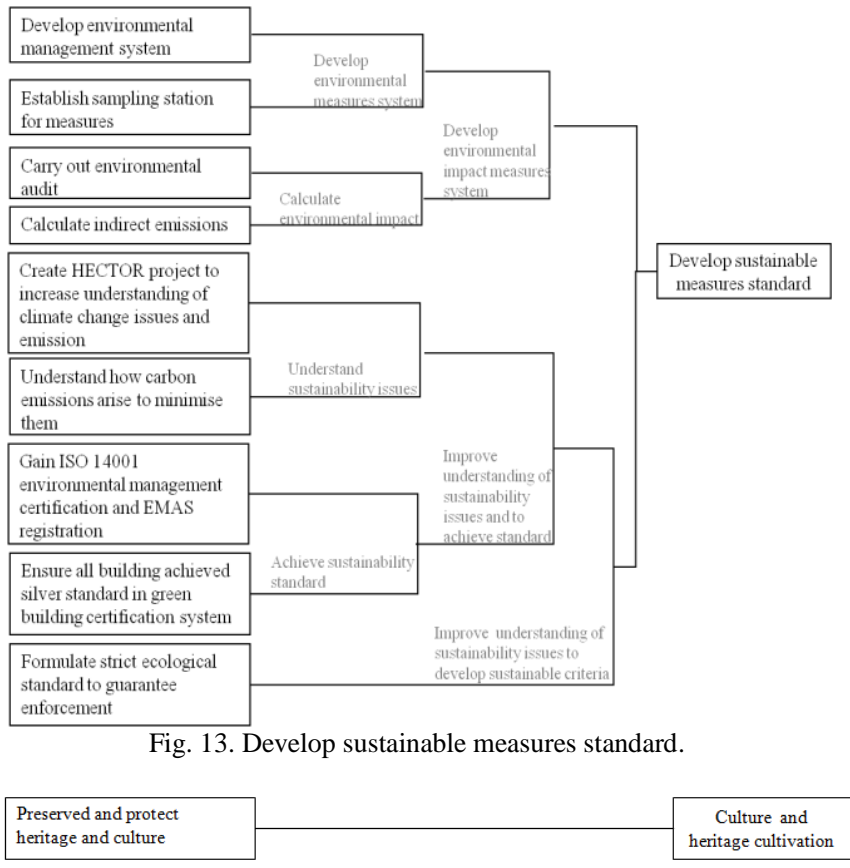

Fig. 14. Culture and heritage cultivation.

Fig. 13 shows the theme - develop sustainable measure standards. This conclude by nine sustainable practices: develop environmental management system, establish sampling station for measures, carry out environmental audit, calculate indirect emissions, increase understanding of climate change issues and emission, understand how carbon emissions arise to minimize them, gain environmental management certificate. Ensure all building apply green concept and formulate strict ecological standard to guarantee enforcement.

Fig. 14 presented that cultivation of culture and heritage of host country is one of the important sustainable practices in 
order to preserve and promote local identity to tourist.

As shown in Fig. 15, one of the ways to achieve sustainability is to develop green economy. This theme is concluding from the sustainable practices such as emphasize smart travel and develop environmental criteria for all the key criteria of supply chain.

\begin{tabular}{|l|l|l|}
\hline Emphasize smart travel \\
\hline $\begin{array}{l}\text { Develop environmental } \\
\text { criteria for all the key criteria } \\
\text { of supply chain }\end{array}$
\end{tabular}

Fig. 15. Development of green economy.

From the 59 sustainable practices that been identify from content analysis, total of 13 themes was created and discussion will be presented in the following section.

\section{DISCUSSIONS}

Based on the effort that had been done by Olympic Games to achieve sustainability in such an international major sport event, content analysis that carried out in this study had segmented sustainable practices of Olympic Games into 14 themes. From these themes, 6 attributes of sustainable event has been drawn as presented in Table II.

TABLE II: ATTRIBUTES OF SUSTAINABLE EVENT

\begin{tabular}{ll}
\hline \hline Attribute & Theme \\
\hline 1) Event as A Tool for & - Adopt concept of zero-waste management \\
Sustainable & practices \\
Development & - Apply sustainable approach in energy \\
& management \\
& - Apply Concept of Zero-emission \\
& - Encourage Environmental Regeneration \\
& and Diversity \\
& - Adopt Environmental-friendly Water \\
& System \\
& - Improve Transportation System \\
2) Sustainable Venue & - Culture and Heritage Cultivation \\
Design & Planning \\
& - Local Resources as First Consideration \\
3) Greening Product & - Development of Green Economy \\
and Services & \\
4) Measure Event & - Develop Sustainable Measures Standard \\
Sustainability & \\
5) Knowledge Sharing & - Raise Public Awareness at All Level \\
at All level & - Share Knowledge of Sustainable Practices \\
& with Stakeholders \\
\hline \hline
\end{tabular}

\section{A. Event as a Tool for Sustainable Development}

Event can be used as a tool to promote sustainable development because it able to ensure the organizer to conduct event activities in an environmentally sustainable manner such as adopting concept of environmental-friendly management for solid-waste, energy, transportation and water. Besides that, event should be used in addressing other social economic priorities such as the cultivation of culture and heritage, fight against poverty and the spread of virus and diseases, and in the promotion of social justice, human well-being and gender equality. Furthermore, toolkits should be created for the event organizer to assist them in developing opportunities to promote sustainable development, and in developing appropriate action plans to address particular priorities and challenges.

\section{B. Sustainable Venue Design}

Respect for the environment in venue design is an integral part of the sustainable development of a sustainable event. There must be clear delineation of roles and responsibilities in planning, design and implementation and ongoing management and operations because the delivery of a positive and sustainable requires early planning and long-term vision. Materials for building venues infrastructure should firstly consider local resources. It is important to use local resources because it will minimize transport and manufacturing energy and air pollution and also creates local employment. The more localized the event, the more money stays within the community.

\section{C. "Greening" Product and Services}

Event organizers must clearly define and communicate, both internally and externally, their sustainable objectives and priorities with suppliers because sustainability will be achieved when its emphasized and promoted throughout the entire "product chain" of supplies, products and service that are associated with an event and facilities. Appropriate guidance such as developing environmental criteria for all the key criteria of supply chain and decision-making systems should be put in place to lead all partners towards a strong performance in these areas. The green procurement policies and tools must be disseminated to all public authorities and other partners. Introduction of smart travel to spectators able to reduce pollution that cause by transportation.

\section{Measuring Event Sustainability}

Development of event impact project is relevant to the overall sustainability in order to measure the impact that caused by event. However, one needs to increase the understanding of climate change issues and emissions in order to develop the environmental audit systems. Integrating information of impacts that caused by event in environmental, social and economic into management and decision-making processes is fundamental for a positive legacy of every event. Besides that, formulation of strict ecological standard is needed to guarantee the enforcement.

\section{Knowledge sharing at all level}

Organizer must build strong relationships with all the stakeholders including the local authorities, sponsors, suppliers, private sectors and community. Close communication between the organizers, sponsors and suppliers is essential in order to make the most opportunities to build a strong sustainable event and to provide more sustainable products and services. It is important to ensure service providers and sponsors endorse the environmental policy and support it from the early stages of planning to avoid problems occurs later. Involvements of local community from outset are essential for the success of raising the awareness of sustainability. Besides that, transfer of knowledge must take place from one event to another event and remain active beyond the event to showcase their successful sustainable activities to increase confidents of other sponsors to support such event.

\section{CONCLUSION}

Through the knowledge that learned from Olympic 
Games, this study can clearly see how the organizers of the Games provide support to ensure the Games to have a minimum impact and a positive legacy on residents of host cities. Moreover, it also showed how an international event such as Olympic Games can be influential in promoting and managing sustainable development in sport and beyond the immediate world of the Games. Since Olympic Games is a well established major event in the world, other event management able to learn from the Olympic Games organizer in term of their effort in organizing a sustainable event. Attributes that formed from this study will play as basic criteria for event organizer in examine the sustainability of their event. An event should at least have these six attributes in order to claim it as sustainable event.

\section{REFERENCES}

[1] S. S. Kimberly. "Growth politics, urban development, and sports stadium construction in the United States: A case study", in The Stadium and the City, J. Bale and O. Moen, Eds. Keele University Press, Keele, 1995.

[2] H. Harry, "Mega-events, urban boosterism, and growth strategies: An analysis of the objectives and legitimations of the Cape Town 2004 Olympic Bid," International Journal of Urban and Regional Research, vol. 24, no. 2, pp. 439-458, 2000.

[3] F. Miguelez and P. Carrasquer. "The repercussion of the Olympic Games on labour," in The Keys to Success, M. De Moragas and M. Botela, Eds. Barcelona: Centre D'estudis Olimpics I De L'esport, Universitat Autonoma De Barcelona, Barcelona, 1995.

[4] C. M. Hall and J. Hodges, "The politics of place and identity in the sydney 2000 Olympics: Sharing the spirit of corporatism," in Sport Culture and Identity, M. Roche, Ed. Meyer and Meyer Verlag, Aachen, 1998.

[5] J. H. Lenskyj, "Inside the Olympic industry: Power, politics and activism," State of New York University Press, Albany, 2000.

[6] World Commission on Environment and Development (WCED), Our Common Future, Oxford University Press, 1987.

[7] C. Vezzoli and E. Manzini, Design for Environmental Sustainability, London: Springer, 2008.

[8] Organization for Economic Cooperation and Development (OECD). The OECD Three-Year Project on Sustainable Development: A Progress Report, Paris: OECD, 1999.

[9] E. Paul, Economic Growth and Environmental Sustainability, Routledge, London, p. 374, 2000.

[10] Earth Summit, Agenda 21, The United Nations Program of Action from Rio, UN, 1992

[11] International Olympic Committee, Olympic Review, 2007.

[12] International Olympic Committee, Olympic Charter, 1996.

[13] International Olympic Committee, Manual on Sport and the Environment, Lausanne, Switzerland, 1997.

[14] International Olympic Committee, Olympic Movement's Agenda 21, Lausanne, Switzerland, 1999.

[15] T, Kristine and H. Sue. "Information and documentation in the Olympic games," University Lectures on the Olympics, Barcelona: Centre d'Estudis Olímpics (UAB), 2002.
[16] International Olympic Committee, IOC Honored with Champion of the Earth 2007 Award, Lausanne, Switzerland, 2007.

[17] United Nations, Observer Status for the International Olympic Committee in the General Assembly, 2009.

[18] United Nations Environment Program, Independent Environmental Assessment: Beijing 2008 Olympic Games, 2009.

[19] Global Reporting Initiative, Sustainability Reporting Guidelines \& Event Organizers Sector Supplement, 2012

[20] International Organization for Standardization, ISO to Develop Sustainable Event Standard in Run-up to 2012 Olympic, Press Release Ref 1281, 2012.

[21] Lillehammer Organizing Committee, Official Report of the Lillehammer Olympic Games, 1994.

[22] Nagano Organizing Committee, Official Report of the Nagano Olympic Games, 1998.

[23] Sydney Organizing Committee, Official Report of the XXVII Olympiad Sydney 2000 Olympic Games, 2001.

[24] Athens Organizing Committee for the Olympic Games, Official Report of the XXVIII Olympiad Athens 2004 Olympic Games, 2004.

[25] Turin Organizing Committee, Final Report XX Olympic Games Torino, 2006.

[26] Beijing Organizing Committee, Official Report of the 2008 Beijing Olympic Games, 2008.

[27] Vancouver Organizing Committee, Official Report of the 2010 Vancouver Olympic Games, V2010.

[28] Leadership in Energy and Environmental Design, Leadership in Energy and Environmental Design, U.S. Green Building Council, Washington DC, USA, 2012.

[29] London Organizing Committee, A Blueprint for Change, 2012.

[30] K. Klaus, Content Analysis: An Introduction to Its Methodology, 2nd ed. Sage Publications, Thousand Oaks, California, 2004, p. 82.

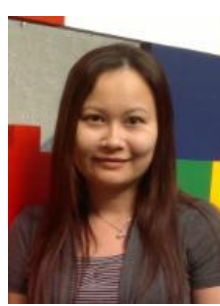

S'harin Binti Mokhtar received the MA degree in art \& design (design technology) and BA (Hons) of art \& design (industrial design) from the Department of Industrial Design, Faculty of Art \& Design, University Technology MARA, Malaysia.

She has worked as a lecturer in the Department of Industrial Design, Faculty of Art \& Design, University Technology MARA, Malaysia for 4 years and currently working toward the Ph.D. degree at the Institute of Creative Industries Design, National Cheng Kung University, Taiwan. Her research interests are product design and sustainable design.

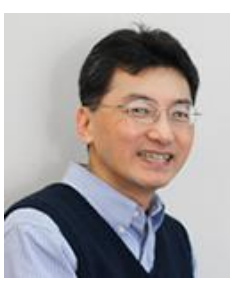

Yi-Shin Deng received his Ph.D. and M.Sc. degrees in industrial engineering from the Department of Industrial Engineering, University of Pittsburgh, Pennsylvania, United States.

$\mathrm{He}$ is an associate professor at National Taiwan University, Taiwan. He is an active researcher and instructor on topics including human-computer interaction, user experience design, social informatics, design theory and methodology and computational design. His other research and practice are on applying user research approach and exploration design processes to ICT device design, social software platform development, and service design are also his research interest. 